\title{
PENGARUH PERLAKUAN SOKLETASI DAN AKTIVATOR KOH TERHADAP KINERJA KARBON AKTIF CANGKANG KELAPA SAWIT SEBAGAI ELEKTRODA SUPERKAPASITOR
}

\author{
Admin Alif*, Olly Norita Tetra, Hermansyah Aziz, dan Hadi Defri \\ Jurusan Kimia, FMIPA, Universitas Andalas Padang \\ Email : olly512@yahoo.com
}

\begin{abstract}
ABSTRAK
Karbon aktif dari limbah cangkang kelapa sawit dapat dimanfaatkan sebagai bahan elektroda superkapasitor. Pada penelitian ini dipelajari pengaruh perlakuan sokletasi dan aktivasi terhadap karbon aktif cangkang kelapa sawit yang dijadikan sebagai bahan elektroda superkapasitor. Perlakuan sokletasi dan aktivasi membuat proses preparasi karbon cangkang kelapa sawit menjadi lebih mudah dibandingkan tanpa perlakuan sokletasi dan aktivasi. Pengaruh sokletasi terhadap kinerja karbon cangkang kelapa sawit sebagai elektroda superkapasitor dilihat dari meningkatnya luas permukaan spesifik 7 kali lebih besar yaitu dari 1,829 $\mathrm{m}^{2} / \mathrm{g}$ menjadi $13,136 \mathrm{~m}^{2} / \mathrm{g}$ dan nilai kapasitansi meningkat 236,82 kali lebih besar dari 0,198 $\mu \mathrm{F}$ menjadi 46,8900 $\mu \mathrm{F}$
\end{abstract}

Kata kunci: Aktivasi, sokletasi, superkapasitor dan carbon cangkang kelapa sawit

\section{PENDAHULUAN}

Superkapasitor merupakan terobosan baru di dunia piranti penyimpan energi yang memiliki rapat daya yang besar, kapasitas penyimpanan muatan yang sangat besar, proses pengisian-pengosongan muatan yang cepat dan tahan lama jika dibandingkan dengan baterai atau kapasitor biasa.( Boyea, J.M., et al . 2007)

Pemanfaatan limbah biji karet yang dimanfaatkan sebagai karbon pada bahan elektroda superkapasitor sebelumnya juga sudah diteliti (Olly, N.T, dkk 2015), karena struktur pori menghubungkankemampuan superkapasitor dalam menyimpan muatan maka karbon berpori potensial untuk digunakan sebagai material elektroda superkapasitor, struktur pori ini bisa didapat dengan melakukan aktivasi terhadap karbon menjadi karbon aktiv karena memiliki potensi kerapatan energi yang tinggi, aksesibilitas pori yang baik, dan biaya pembuatan yang relatif murah. Karbon aktiv dapat dibuat dengan cara karbonisasi bahan alami dan juga bisa dengan menggunakan aktivasi kimia dengan menggunakan asam, basa dan garam, tetapi dari berbagai penelitian aktivasi dengan menggunakan basa $(\mathrm{NaOH}$ dan $\mathrm{KOH})$ akan memberikan struktur pori yang lebih berperan dalam penyimpanan muatan (Emriadi., dkk 2014; Olly, N.T., dkk 2016). Selain struktur pori dari karbon aktif, kapasitas energy dari superkapasitor juga ditentukan oleh jenis elektrolit. Penggunaan karbon dari cangkang kelapa sawit yang dikarbonasi pada suhu 300$400^{\circ} \mathrm{C}$ tanpa aktivasi, dan dihasilkan nilai kapasitansi yang rendah yaitu $41,21 \mu \mathrm{F}$. (Olly, N.T., 2016; Hermansyah, 2016)

Berdasarkan hasil penelitian tersebut, maka pada penelitian ini dipelajari pengaruh aktivasi dan sokletasi dari bahan karbon dari limbah cangkang kelapa sawit sebagai elektroda dengan elektrolit asam pospat $\left(\mathrm{H}_{3} \mathrm{PO}_{4}\right)$. Sokletasi bertujuan untuk menghilangkan kandungan lemak yang ada di cangkang kelapa sawit yang mempengaruhi nilai kapasitansi dan aktivasi berguna untuk membuka dan memperbaiki struktur pori cangkang kelapa sawit sehingga kemampuan dari elektroda untuk menyimpan muatan menjadi lebih besar dari sebelumnya. 


\section{METODE PENELITIAN}

Proses Sokletasi pada Cangkang Kelapa Sawit

Proses sokletasi dilakukan dengan pelarut nheksan selama 5 jam dan cangkang kelapa sawit yang telah disokletasi disiapkan sebagai karbon untuk elektroda superkapasitor. Cangkang kelapa sawit yang telah disokletasi lalu difurnance pada suhu $300^{\circ} \mathrm{C}$.

Persiapan Aktivasi Karbon Cangkang Kelapa Sawit dengan KOH

Cangkang kelapa sawit dikarbonisasi pada suhu $300^{\circ} \mathrm{C}$ selama 4 jam kemudian dihaluskan dan diayak dengan menggunakan ayakan berukuran $45 \mu \mathrm{m}$ dan $63 \mu \mathrm{m}$. Proses aktivasi dilakukan dengan menambahkan $\mathrm{KOH} 10 \mathrm{M}$ yang digunakan sebagai zat pengaktivasi, dengan perbandingan masa karbon dan $\mathrm{KOH}$ 1:4 diaduk hingga $\mathrm{KOH}$ merata dan didiamkan selama 4 jam. Karbon aktif kemudian difurnance pada suhu 300 dan $400^{\circ} \mathrm{C}$ selama 4 jam dan dilakukan pencucian dengan menambahkan $\mathrm{HCl} 0,1 \mathrm{M}$ sampai $\mathrm{pH} 7$, dan dilanjutkan pencucian dengan akuades. Karbon aktif yang didapat dipanaskan pada suhu $\pm 105^{\circ} \mathrm{C}$ (Chaitra $\mathrm{K}$ 2016 ; Hartono, dkk 2010].

\section{Karakterisasi Pada Karbon Cangkang Kelapa Sawit}

Karbon aktif cangkang kelapa sawit dikarakterisasi dengan menggunakan X-Ray Diffraction (XRD), Scanning Electron Microscopy - Energy Dispersive X-Ray (SEM-EDX), dan Surface Area Analyzer (SAA).

\section{Perakitan Plat Elektroda Superkapasitor}

Rangkaian superkapasitor plat disusun seperti Gambar 1. Masing-masing kertas batang padi dilapisi dengan karbon aktif cangkang kelapa sawit yang dijadikan sebagai elektroda. Kedua elektroda disusun seperti sandwich yang dipisahkan oleh separator PVA (Polivinil Alkohol) di bagian tengahnya. Kedua plat elektroda diapit lempengan tembaga

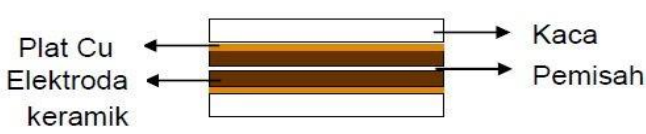

Gambar 1 .Rangkaian Superkapasitor Metoda Plat / Sandwich
Pengukuran Sifat Listrik dari Rangkaian Superkapasitor

Pengukuran sifat listrik dilakukan dengan menggunakan LCR-Meter dan Multimeter

HASIL DAN PEMBAHASAN

Karakterisasi Karbon Cangkang Kelapa Sawit sebagai Bahan Elektroda

a. X-Ray Diffraction (XRD)

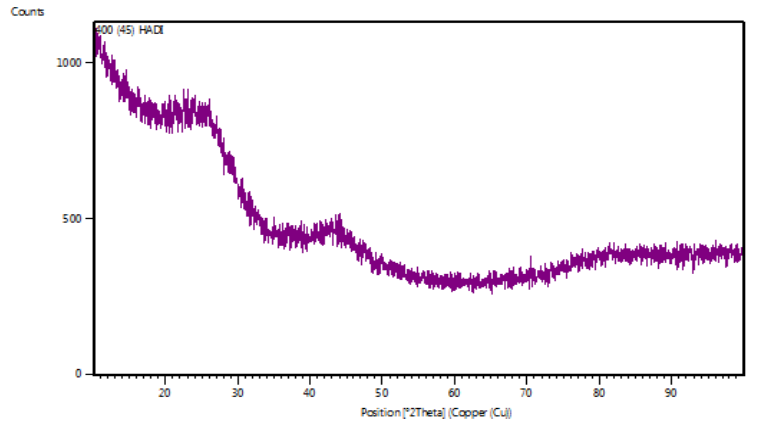

Gambar 2. Pola difraksi karbon cangkang kelapa sawit dengan suhu pembakaran $400^{\circ} \mathrm{C}$.

Gambar 2, menunjukkan bahwa struktur karbon cangkang kelapa sawit berbentuk amorf, Pola difraksi memperlihatkan 2 puncak difraksi dengan nilai $2^{\circ}$ sekitar $22-24^{\circ}$ dan $42-44^{\circ}$ yang mana ini juga sesuai dengan pola difraksi dari grafit (Hermansyah ,dkk 2016).

\section{b. Scanning Electron Microscopy (SEM)}

Gambar 3. adalah hasil karakterisasi SEM dari karbon cangkang kelapa sawit dan didapatkan bahwa morfologi permukaan dari karbon cangkang kelapa sawit berupa granular. Struktur pori karbon tanpa perlakuan aktivasi dan sokletasi lebih kecil dibandingkan dengan karbon aktivasi dan sokletasi. Ini mengindikasikan bahwa dengan adanya perlakuan sokletasi dan aktivasi terhadap karbon cangkang kelapa sawit akan membuat pori tersebar merata, menghilangkan pengotor sehingga memperluas volume pori, dan meningkatkan luas permukaan dari cangkang kelapa sawit. 


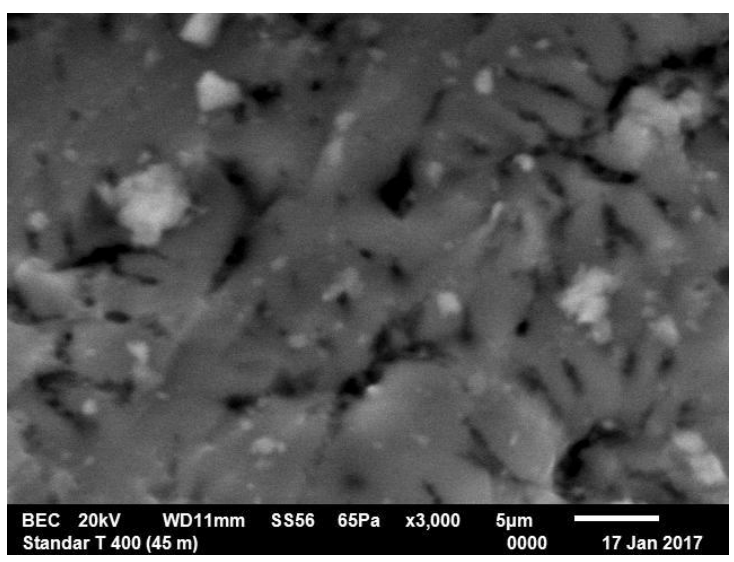

a.

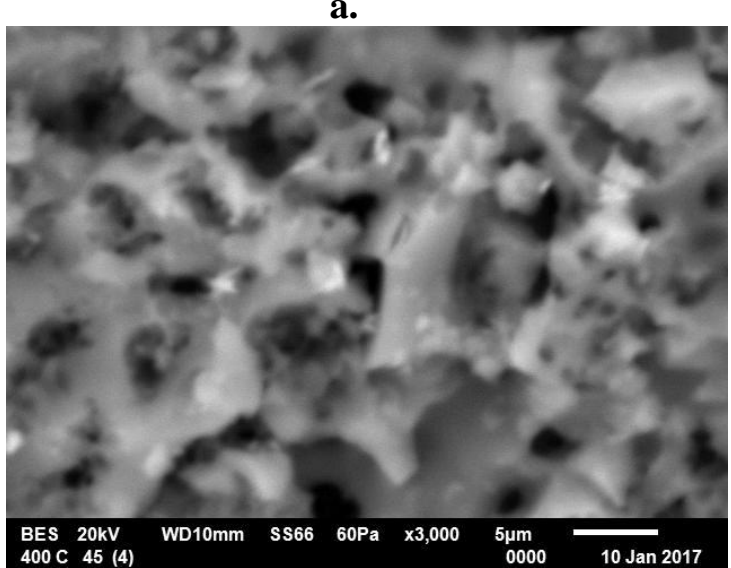

b.

Gambar 3. Hasil Karakterisasi SEM dengan perbesaran 3000 kali pada karbon cangkang kelapa sawit pada suhu pembakaran $400^{\circ} \mathrm{C}$ dengan ukuran partikel $45 \mu \mathrm{m}$ a. tanpa aktivasi dan sokletasi, b. aktivasi dan sokletasi.

\section{c. Energy dispersive X-Ray (EDX)}

Analisis EDX terhadap karbon dari cangkang kelapa sawit menunjukkan komposisi material yang terdapat pada karbon tersebut. Tabel 1 . menunjukkan kandungan karbon dari cangkang kelapa sawit dengan menggunakan EDX. Komposisi paling banyak yang terkandung dalam karbon dari cangkang kelapa sawit adalah unsur karbon. Unsur kalsium dan silika berasal dari mineral yang terkandung dalam karbon cangkang kelapa sawit karena bahan dasar karbon berasal dari bahan alam. (Kurniati E, dkk 2008) . Komposisi unsur kalsium dan silika sangat kecil dan untuk unsur kalium berasal dari aktivator $\mathrm{KOH}$ yang masih tersisa dikarbon aktif. Pada Tabel 1 terlihat bahwa pengaruh delipidasi dan aktivator $\mathrm{KOH}$ pada karbon cangkang kelapa sawit meningkatkan persen massa karbon hingga 11,78 \% yaitu dari 77,66 $\%$ menjadi 88,03 \%. Aktivasi dan delipidasi dapat mengurangi kadar air yang terkandung di dalam karbon cangkang kelapa sawit. Kandungan air lebih banyak menguap dengan perlakuan aktivasi dan delipidasi.

Tabel 1. Komposisi material yang terkandung di dalam karbon cangkang kelapa sawit pada suhu pembakaran $400{ }^{\circ} \mathrm{C}$.

\begin{tabular}{|c|c|c|c|}
\hline \multirow[b]{3}{*}{ Unsur } & \multicolumn{3}{|c|}{$\%$ Berat } \\
\hline & & Perlakuan & \\
\hline & $\begin{array}{c}\text { Tanpa } \\
\text { Aktivasi } \\
\text { dan } \\
\text { Delipidasi }\end{array}$ & Aktivasi & $\begin{array}{c}\text { Aktivasi } \\
\text { dan } \\
\text { Delipidasi }\end{array}$ \\
\hline $\mathrm{C}$ & 77,66 & 72,12 & 88,03 \\
\hline $\mathrm{O}$ & 22,14 & 20,39 & 10,10 \\
\hline $\mathrm{Si}$ & 0,12 & 0,26 & 0,27 \\
\hline $\mathrm{Cl}$ & - & - & 0,11 \\
\hline $\mathrm{Ca}$ & - & 0,24 & - \\
\hline K & & 6,99 & - \\
\hline
\end{tabular}

Pengaruh Delipidasi dan Aktivasi

Tabel 2. Luas permukaan spesifik dari karbon cangkang kelapa sawit pada suhu pembakaran $400^{\circ} \mathrm{C}$

\begin{tabular}{l|l|l}
\hline Perlakuan & $\begin{array}{l}\text { Luas } \\
\text { permukaan } \\
\text { spesifik } \\
\left(\mathbf{m}^{2} / \mathbf{g}\right)\end{array}$ & $\begin{array}{l}\text { Kapasita } \\
\mathbf{n s i}(\boldsymbol{\mu} \mathbf{F})\end{array}$ \\
\hline $\begin{array}{l}\text { tanpa diaktivasi, } \\
\text { tanpa delipidasi }\end{array}$ & 1,829 & 0,1980 \\
$\begin{array}{l}\text { diaktivas, tanpa } \\
\text { delipidasi }\end{array}$ & 27,253 & 48,2516 \\
$\begin{array}{l}\text { diaktivas dan } \\
\text { delipidasi }\end{array}$ & 13,136 & 46,8900 \\
\hline
\end{tabular}

Pada Tabel 2, terlihat bahwa pengaruh delipidasi dan aktivasi dapat meningkatkan luas permukaan 7 kali lebih besar dibandingkan tanpa yang diaktivasi yaitu dari $1,829 \mathrm{~m}^{2} / \mathrm{g}$ menjadi $13,136 \mathrm{~m}^{2} / \mathrm{g}$. Aktivasi bertujuan membuka atau memperbesar pori yaitu dengan cara memecahkan ikatan pada rantai karbon atau mengoksidasi molekulmolekul permukaan sehingga karbon mengalami perubahan sifat baik fisika maupun kimia yaitu luas permukaannya bertambah besar.( Yacob A R, et al, 2008) 
Delipidasi dengan metoda sokletasi dilakukan untuk menghilangkan lipid atau minyak pada cangkang kelapa sawit. Pada penelitian ini proses delipidasi dengan metoda sokletasi tidak menaikkan nilai kapasitansi karena proses delipidasi membuat gugus fungsi yang terkandung pada minyak hilang sehingga jumlah gugus fungsi pada karbon cangkang kelapa sawit berkurang yang akan mengurangi kemampuan karbon cangkang kelapa sawit menyimpan muatan menurun. Delipidasi membuat proses preparasi menjadi lebih mudah. Kandungan minyak cangkang kelapa sawit berdasarkan literature yaitu 7,4781\%. Pada penelitian ini didapat kandungan minyak yaitu 3,237\%. Perbedaan persen kadar minyak cangkang kelapa sawit ini dipengaruhi oleh asal sawit yang disokletasi, kondisi tanah tempat cangkang sawit tersebut diambil dan nilai mutu dari minyak sawit tersebut.

Pengukuran Sifat-sifat Listrik dari Elektroda Superkapasitor Berbahan Dasar Karbon Cangkang Kelapa Sawit.

a. Pengaruh Ukuran Partikel Karbon Cangkang Kelapa Sawit terhadap Nilai Kapasitansi dari Elektroda Superkapasitor

Gambar 4. menunjukkan bahwa semakin besar luas permukaan suatu elektroda, maka semakin besar nilai kapasitansi. Hal ini disebabkan karena semakin besar luas permukaan elektroda, maka semakin besar kemampuan elektroda tersebut untuk menyimpan muatan. Luas permukaan elektroda yang besar akan menyediakan tempat untuk penyimpanan muatan untuk membentuk lapis rangkap listrik pada permukaan elektroda tersebut ( Sun, etal, 2016).

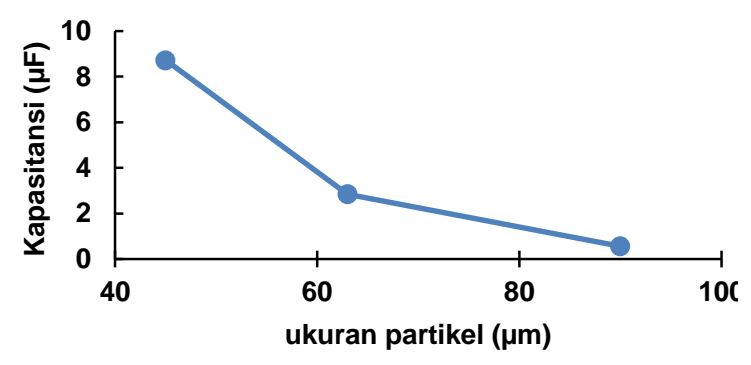

Gambar 4. Pengaruh ukuran partikel karbon cangkang kelapa sawit terhadap nilai kapasitansi dari elektroda superkapasitor
Superkapasitor dengan ukuran partikel $45 \mu \mathrm{m}$ memiliki nilai kapasitansi maksimum yaitu 8,633 $\mu \mathrm{F}$ dengan nilai 15 kali lebih tinggi dibandingkan dengan superkapasior dengan ukuran partikel $90 \mu \mathrm{m}$ dengan nilai kapasitansi yaitu $0,563 \mu \mathrm{F}$. Hal ini disebabkan karena luas permukaan karbon cangkang kelapa sawit ukuran $45 \mu \mathrm{m}$ lebih besar dibandingkan dengan ukuran partikel $63 \mu \mathrm{m}$ dan $90 \mu \mathrm{m}$, sehingga kemampuannya menyimpan muatan lebih besar dibandingkan karbon cangkang kelapa sawit ukuran partikel $60 \mu \mathrm{m}$ dan $90 \mu \mathrm{m}$.

\section{b. Pengaruh Luas Permukaan Plat Elektroda Karbon Cangkang Kelapa Sawit Terhadap Nilai Kapasitansi dari Elektroda Superkapasitor}

Luas permukaan elektroda berpengaruh terhadap nilai kapasitansi. Semakin besar ukuran plat semakin meningkat kemampuannya dalam menyimpan muatan.

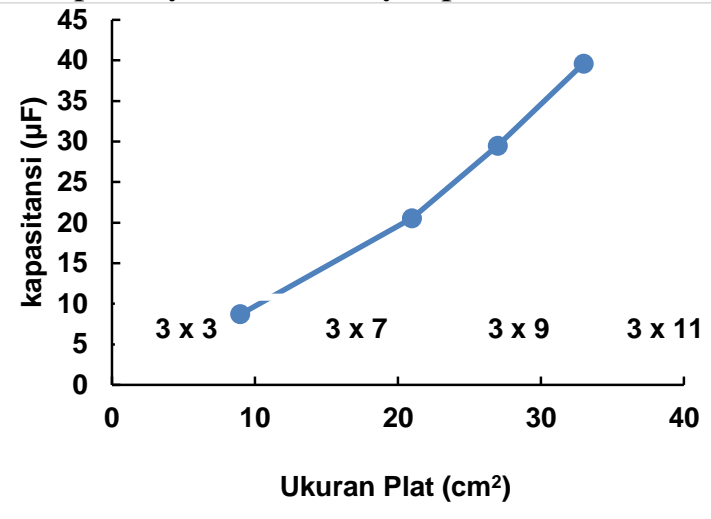

Gambar 5. Pengaruh luas permukaan plat elektroda karbon cangkang kelapa sawit terhadap nilai kapasitansi dari elektroda superkapasitor

Gambar 5. menunjukkan bahwa semakin besar luas plat elektroda, maka semakin besar nilai kapasitansi. Hal ini disebabkan karena semakin besar luas plat elektroda, maka semakin besar kemampuan elektroda tersebut untuk menyimpan muatan karena bertambahnya jumlah pori karbon untuk menyimpan muatan (Olly, N.T, 2016 ; Hermansyah dkk, 2016). Luas permukaan plat elektroda yang besar akan menyediakan tempat untuk penyimpanan muatan membentuk lapis rangkap listrik pada permukaan elektroda tersebut. 


\section{c. Pengaruh Konsentrasi Elektrolit Elektroda Karbon Cangkang Kelapa Sawit Terhadap Nilai Kapasitansi dari Elektroda Superkapasitor}

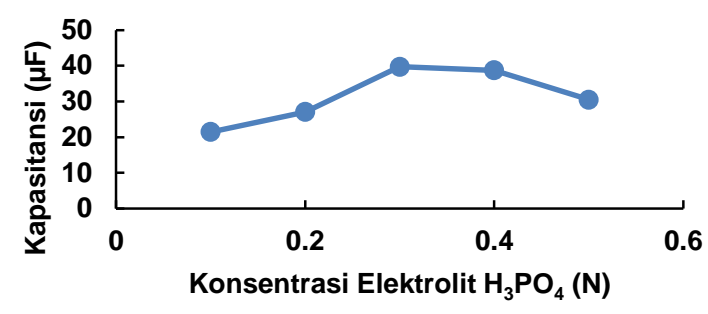

Gambar 6. Pengaruh konsentrasi elektrolit $\mathrm{H}_{3} \mathrm{PO}_{4}$ terhadap nilai kapasitansi dari elektroda superkapasitor

Larutan elektrolit yang semakin asam juga akan merusak karbon cangkang kelapa sawit pada kertas karbon, dan juga separator PVA karena lapisan tipis PVA dapat mengalami perubahan bentuk (swelling). Meningkatnya keasaman sehingga menurunkan kekuatan mekanik dari PVA dan mengganggu mobilitas ion-ion pada proses pembentukan lapisan rangkap listrik pada permukaan elektroda ( Hermansyah, dkk 2016).

Superkapasitor dengan konsentrasi elektrolit $0.3 \mathrm{~N}$ memiliki nilai kapasitansi maksimum yaitu 30,694 $\mu \mathrm{F}$ dengan nilai hampir 2 kali lipat lebih tinggi dibandingkan dengan superkapasitor dengan konsentrasi 0.1 N.

\section{Pengaruh Konsentrasi Elektrolit $\mathrm{H}_{3} \mathrm{PO}_{4}$ terhadap Konduktivitas dari Elektroda Superkapasitor}

Nilai konduktivitas ditentukan berdasarkan nilai resistansi yang terukur pada superkapasitor pada luas permukaan elektroda optimum yaitu elektroda dengan ukuran kertas karbon 3 x $11 \mathrm{~cm}^{2}$.

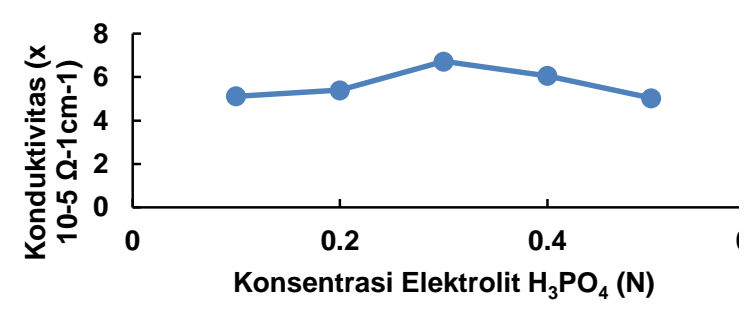

Gambar 7. Pengaruh konsentrasi elektrolit $\mathrm{H}_{3} \mathrm{PO}_{4}$ terhadap konduktivitas dari elektroda superkapasitor.
Gambar 7. Menunjukkan konduktivitas maksimum pada konsentrasi elektrolit $\mathrm{H}_{3} \mathrm{PO}_{4}$ $0,3 \mathrm{~N}$ yaitu $6,723 \quad \Omega^{-1} \mathrm{~cm}^{-1}$, kemudian mengalami penurunan pada konsentrasi elektrolit $\mathrm{H}_{3} \mathrm{PO}_{4} 0,4 \mathrm{~N}$ dan $0,5 \mathrm{~N}$.

\section{d. Pengaruh Lama Waktu Pengisian pada Elektroda terhadap Nilai Kapasitansi dari Elektroda Superkapasitor}

Semakin lama waktu pengisian maka semakin banyak muatan yang tersimpan sehingga nilai kapasitansi akan meningkat pada penelitian waktu pengisian dilakukan dengan menggunakan charger Nokia $5 \mathrm{~V}$.

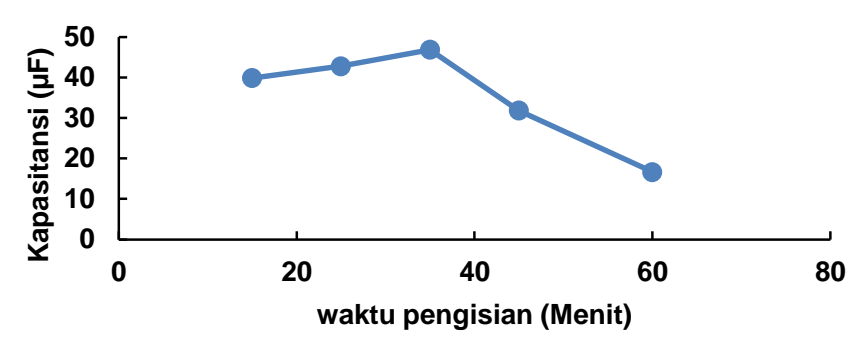

Gambar 8. Pengaruh waktu pengisian pada elektroda terhadap nilai kapasitansi dari elektroda superkapasitor

Gambar 8. menunjukkan bahwa semakin lama waktu pengisian maka nilai kapasitansi dari elektroda superkapasitor semakin meningkat yaitu $46,89 \mu F$. Setelah waktu 35 menit nilai kapasitansi menurun karena pada saat pengisian 35 menit semua ion-ion dalam separator telah bergerak kepermukaan elektroda untuk membentuk lapisan rangkap listrik.

Hubungan Kapasitansi, Muatan, dan Jumlah Elektron pada Variasi Konsentrasi Elektrolit dari Elektroda Superkapasitor

Tabel 3. Hubungan Kapasitansi, Muatan, dan Jumlah Elektron pada Variasi Konsentrasi Elektrolit dari Elektroda Superkapasitor

\begin{tabular}{|c|c|c|c|}
\hline $\begin{array}{c}{\left[\mathrm{H}_{3} \mathrm{PO}_{4}\right]} \\
(\mathrm{N})\end{array}$ & $\begin{array}{c}\text { Kapasitansi } \\
(\mu \mathrm{F})\end{array}$ & $\begin{array}{c}\text { Muatan } \\
(\mathrm{C})\end{array}$ & $\begin{array}{c}\text { Jumlah } \\
\text { Elektron } \\
(\mathrm{e}-)\end{array}$ \\
\hline 0,1 & 21,435 & 2,076 & $\begin{array}{c}129,082 \mathrm{x} \\
10^{17}\end{array}$ \\
\hline
\end{tabular}




\begin{tabular}{|c|c|c|c|}
\hline 0,2 & 27,040 & 2,619 & $\begin{array}{c}162,835 \mathrm{x} \\
10^{17}\end{array}$ \\
\hline 0,3 & 39,694 & 3,844 & $\begin{array}{c}239,037 \mathrm{x} \\
10^{17}\end{array}$ \\
\hline 0,4 & 38,706 & 3,748 & $\begin{array}{c}233,088 \mathrm{x} \\
10^{17}\end{array}$ \\
\hline 0,5 & 30,480 & 2,952 & $\begin{array}{c}183,551 \mathrm{x} \\
10^{17}\end{array}$ \\
\hline
\end{tabular}

Tabel 3 menunjukkan bahwa semakin besar kapasitansi, maka semakin besar pula muatan yang tersimpan dan elektron yang mengalir dari larutan elektrolit ke elektroda juga semakin banyak. Muatan maksimum ada pada konsentrasi elektrolit $0,3 \mathrm{~N}$ dengan jumlah muatan $239,037 \times 10^{17} \mathrm{e}^{-}$.

\section{KESIMPULAN}

Karbon aktif dari perlakuan sokletasi dan aktivasi memiliki luas permukaan spesifik $13,136 \mathrm{~m}^{2} / \mathrm{g}$. Pengaruh aktivasi dengan $\mathrm{KOH}$ setelah sokletasi adalah terjadinya peningkatan nilai kapasitansi dan konduktivitas. Pada elektroda yang diaktivasi dengan $\mathrm{KOH}$ memberikan nilai kapasitansi maksimum pada ukuran partikel $45 \mu \mathrm{m}$ $(8,726 \mu \mathrm{F})$ dengan waktu pengisian 15 menit dan konsentrasi elektrolit 0,3 N. Sedangkan nilai kapasitansi optimum yaitu $46.89 \mu \mathrm{F}$ pada ukuran plat $3 \times 11 \mathrm{~cm}$, waktu pengisian optimum 35 menit dan konsentrasi elektrolit $\mathrm{H} 3 \mathrm{PO} 4$ adalah $0,3 \mathrm{~N}$.

\section{DAFTAR RUJUKAN}

Boyea, J.M., Camacho, R.E., Turano, S. P., And Ready, W. J., (2007), Carbon Nanotube-Based Supercapacitors: Technologies and Markets, Nanotechnology Law \&Business; 585 593

Olly, N.T., Admin, A., dan Gesti. U., (2015), Pemanfaatan Limbah Tempurung Biji Karet Sebagai Bahan Elektroda Superkapasitor, Laporan Penelitian Dosen Muda, Universitas Andalas, Padang

Emriadi, Muttaqin, A., Alif, A., Norita Tetra, (2014), Pemanfaatan Nanokomposir Resin dari Getah Damar untuk Bahan Superkapasitor yang Ramah
Lingkungan, Laporan Penelitian Unggulan Perguruan Tinggi, Universitas Andalas, Padang

Olly, N.T., Emriadi., Admin, A., Hermansyah. A., Hanif. W., (2016), Der Pharma Chemica, 8(17):26-30

Hermansyah, Aziz., Olly, N.T., Admin, A., Syukri., and Wahyu, R.,( 2016), Der Pharma Chemica, 8(15):227-232

Kurniati E, (2008), Jurnal Penelitian Ilmu Teknik, vol 8, No 2 Desember : $96-$ 103.

Chaitra K, Vinny R T, Sivaraman P, Narendra Reddy, Chunyan Hu, Krishna Venkatesh, Vivek C S, Nagaraju N, Kathyayini N., (2016), Journal of Energy chemistry, 6(28): 1-7.

Hartono, Singgih dan Ratnawati, (2010), Jurnal Sains Materi Indonesia, 12 (1): 12-16.

Yacob A R, Majid Z A, Dewi R S, Inderan., (2008), The Malaysian Journal of Analytical Sciences, 12(1):264-271.

Sun, Fei, Jihui Gao, Xin Liu, Xinxin Pi, Yuqi Yang, Shaohua Wu. 2016, Journal of Applies Surface Science, 857-863

Chao P, Xing-bin Y, Ru-tao W, Jun-wei L, Yu-jing O, Qun-ji X., (2013), Electrochimica Acta 401-408.

Olly, N.T., Admin, A., dan Emriadi., (2015), Pengaruh Suhu Pembakaran Terhadap Pembentukan Elektroda Superkapasitor $\mathrm{TiO}_{2} / \mathrm{C}$ Berpendukung Keramik Melalui Metoda Sol Gel, Laporan Penelitian Unggulan Perguruan Tinggi, Universitas Andalas, Padang

Barmawi, I., Taer, E., Umar A. I., (2011), Jurnal Fisika Himpunan Fisika Indonesia, 11:1-5.

Choudhury, N. A., Sampath, S., Shukla, K., (2008). Hydrogel-Polymer Electrolytes for Electrochemical Capacitors : An Overview, Energy And Environmental Science, 2:55-56

Rossi, M., Iskandar, F., Abdullah, M., Khairurrijal., (2014), Int. J. Electrochem.Sci., 9:4251-4256. 